\title{
Teatro popular no Brasil A rua como âmbito da cultura popular
}

\author{
Dr. André Luiz Antunes Netto Carreira \\ Universidade do Estado de Santa Catarina - UDESC \\ Conselho Nacional de Desenvolvimento Científico e Tecnológico - CNPq
}

Convidado pelo Programa de Pós Graduação em Teatro da UNIRIO a refletir sobre o tema teatro popular no Brasil imediatamente pensei em abordar a relação entre a modalidade do teatro de rua, que é uma das áreas nas quais tenho trabalhado muito nos últimos anos, e diversas formulações conceituais referentes à idéia de teatro popular.

A questão que pretendo abordar focaliza a definição de qual é o âmbito ou zona onde podemos pensar a relação teatro de rua / teatro popular.

Talvez não seja uma novidade propor uma clara diferenciação entre a idéia de teatro popular e do teatro de rua. De forma reiterada, estudiosos do teatro se referem ao teatro de rua como um componente do teatro popular. Mas de fato, quando nos debruçamos sobre o teatro de rua contemporâneo podemos ver uma miríade de projetos cênicos que exploram formas teatrais que se relacionam muito mais com experimentações vanguardistas do que com a cultura popular.

O que nos intriga é que percebemos a rua como um lugar da cultura popular. Portanto, nos inclinamos a pensar que as manifestações espetaculares neste âmbito devem estabelecer relações com este campo cultural que delimitamos como popular

Se há um vínculo entre o campo da cultura popular o e o teatro de rua, este vínculo se manifesta nos sentidos do uso da rua, na possibilidade de apropriação e transformação dos usos da rua, até mesmo em uma lógica da rua.

A rua, enquanto espaço de convivência, permite que o cidadão desfrute

${ }^{2}$ Duvignaud, Jean. El juego del juego. México. 1982. Fondo de Cultura Económica. p.18.

3 Duvignaud, Jean. El juego del juego. p. 12.

${ }^{4}$ Ávila, Affonso. O lúdico e as projeções do mundo barroco. São Paulo. 1980. De. Perspectiva. 
de um anonimato que o libera do peso do compromisso pessoal. No espaço aberto da rua e em comunidade, o ser humano urbano se sente mais capaz de atuar. Este é um comportamento que facilita que na rua exista uma predisposição para o jogos e a participação espontânea.

O jogo foi definido pelo sociólogo francês Jean Duvignaud "como uma atividade sem objetivos conscientes, um estado de disponibilidade que foge a toda intenção utilitária"2, livre e sem regras (...) "neste estado de ruptura do ser individual ou social, no qual a única coisa que não se questiona é a arte."”3

O jogo, a brincadeira é fantasia. As crianças transformam a calçada de sua rua na praia à qual chegam piratas. Os adultos transformam, durante uma festa de carnaval, as pedras do calçamento, no âmbito onde cada um pode ser o que quiser. A rua, é portanto, o espaço para o exercício da liberdade e da criatividade.

No que se refere ao comportamento do homem da rua, convivem duas tendências: a primeira é uma atitude de respeito às regras sociais dominantes, e a segunda á a abertura ao jogo e à liberdade de ação. $\mathrm{O}$ equilíbrio entre a atitude social dominante e o jogo é dinâmico, e se modifica de acordo com os processos sócio-culturais do momento.

$\mathrm{Na}$ rua existe um complexo jogo social no qual está presente uma infinidade de inter-relações que regem grande parte do comportamento dos cidadãos na rua. Este ordenamento não é imutável e portanto, é permeável à ação coletiva anteriormente descrita, e se transforma segundo a incidência dos acontecimentos.

A tendência ao jogo se vê favorecida especialmente pela individualização, que é provocada pela sensação de liberdade. Paradoxalmente, é através do jogo da rua - manifestado nas ações coletivas - que o indivíduo se expressa sem freios e limitações. O jogo quando "evolui da sua esfera de fenômeno subjetivo individual e penetra as estruturas da vida social"4 se faz transgressor, porque a mobilização da energia lúdica coletiva questiona os códigos e as regras sociais estabelecidas. Ao se materializar na superfície do ser social, o jogo se plasma em manifestações culturais de ruptura da ordem vigente.

Este jogo da rua, cujo exemplo mais contundente talvez seja o carnaval, abre a possibilidade da mais ampla liberdade criadora, porque, enquanto dura, põe o mundo de cabeça para baixo, inverte todos os valores. Nossa sociedade

${ }^{5}$ Duvignaud, Jean. El juego del juego. p.54. 
estabeleceu como regra que as ruas cumprem uma série de funções específicas, e aquelas atividades que extrapolam estes limites entram numa zona de conflito, pois, questionam não somente o uso da rua, senão o poder de controle sobre o espaço cidadão.

O jogo, enquanto experiência lúdica, é em essência questionador. Subverte a ordem que propicia tranqüilidade, e a desequilibra. É esta a característica que define o jogo como um elemento perigoso que deve ser enquadrado como um fenômeno temporário para seu controle. Jean Duvignaud fazendo referência ao jogo com relação às festas como acontecimentos únicos diz: "Durante esta explosão súbita e momentânea das relações humanas estabelecidas, se rompe o consenso, se apagam os modelos culturais transmitidos de geração em geração, não por uma transgressão qualquer, senão porque o ser descobre, às vezes com violência, uma plenitude ou uma super abundância proibida na vida cotidiana...lógico, a festa não dura. É perecível no seu próprio princípio". 5 No carnaval, as mais amplas liberdades estão contidas em quatro dias.

As manifestações políticas de rua não controladas por aparelhos políticos, quando alcançam o grau de revolucionárias, isto é, quando põe em risco o sistema de dominação sócio-político, atingem a mesma liberdade do carnaval, pois as regras desaparecem e a criatividade se faz livre. Neste caso, independente dos objetivos específicos da manifestação, aparece uma enorme variedade de reações que estão muito mais relacionadas com a possibilidade de jogar; já seja o papel de transformador da realidade ou simplesmente pôr para fora uma energia por muito tempo contida.

É esta característica de ruptura, própria do comportamento oriundo do jogo, que provoca que o espaço da rua seja considerado estratégico pelos organismos encarregados de manter a ordem social. Por isso o teatro de rua, ainda que não possa alcançar a dimensão do descontrole do carnaval ou a força avassaladora das grandes manifestações sindicais, explicita a possibilidade de ruptura ao provocar o jogo e ao convidar aos transeuntes a participar da criação - ainda que momentânea - de uma nova ordem.

Isso ganha importância por se tratrar de um fenômeno instalado em um espaço de vivência cotidiana - que diferentemente das salas teatrais - não enclausura os espectadores, senão que, ao ser totalmente aberto, estreita a

\footnotetext{
${ }^{6}$ Vetor no sentido explicitado por Marco de Marinis: força dramática que opera na modificação dos personagens.
} 
relação entre o acontecimento teatral e o horizonte da cidade, provocando um imediato desdobramento dos signos propostos pelo espetáculo.

Considerando a cultura popular como um conjunto de produção simbólica que se constrói também como imagem especular da cultura "culta", uma questão pertinente segundo Fredric Jameson, seria averiguar se ambos movimentos culturais não se definem apenas como coisa relacionada com este outro.

Então a cultura da rua que se relaciona estreitamente com a idéia de jogo aparece delimitada pelas fronteiras da cultura de entre muros, a cultura da instituição do interior dos edifícios. É o adentro e o afora que permitirá a construção um saber/fazer diferenciado.

A rua, por ser o espaço da circulação pública, onde estão desde o marginal até o trabalhador de setores médios, constitui um espaço de hibridação de usos que dá forma a um marco cultural próprio, mas, que se relaciona - por aproximação - com o campo da cultura popular.

É neste território híbrido que se da a aproximação entre o teatro de rua e a cultura popular. De fato, esta aproximação não é somente temática. Pelo contrário ela se dá no sentido das regras de funcionamento do espetáculo e das modalidades de atenção do público. Isto é, a interferência da audiência tem, neste caso, uma influência muito grande na constituição do espetacular.

Quando falo da audiência (de sua interferência) quero dizer que através das atitudes do público surge um vetor ${ }^{6}$ que representa necessariamente a presença da cultura da rua/popular na cerimônia espetacular.

Como o fazer espetacular não pode desconhecer a força do público na articulação de sentidos do espetáculo, a resultante do teatro de rua terá sempre o elemento popular no seu bojo, ainda quando não o tenha - conscientemente - na sua temática.

Poderíamos dizer que o popular estaria sempre relacionado com o teatro de rua na sua existência enquanto cerimonia social, como acontecimento.

\section{O teatro de rua como transgressão.}

A hierarquização espacial que estabelece a cidade capitalista considera alguns espaços como nobres e outros como marginais. Ao confinar o espetáculo teatral nas salas, a cultura capitalista determinou que o espetáculo aceitaria

\footnotetext{
${ }^{7}$ Melquior, José Guilherme. Formalismo e tradição moderna - O problema da arte na crise da cultura. São Paulo. 1974. De. Forense - EDUSP. p. 158.
} 
perder seu caráter de festa e ganharia o valor de mercadoria. Esta mercadoria tem mais valor nos espaços fechados onde o pagamento de uma entrada, não somente gera lucro, senão que outorga hierarquia. Neste marco, a manifestação teatral na rua ocupa, cada vez mais, um espaço de marginalidade. A expressão desta marginalidade denuncia a cara segregacionista do sistema e portanto o questiona, transgredindo assim as regras do uso espacial da cidade.

Se o espaço profano da rua está reservado especialmente para suas funções específicas, toda atividade que esteja fora deste marco resultará, de certo modo, transgressora. Esta transgressão pode variar segundo graus ou intensidades, mas, ao fim, questionará o sistema dominante. Ainda quando a cultura dominante possa conviver com essa transgressão, cedendo alguns espaços, a expressão da rua continua sendo marginal frente ao conceito de teatro respeitável que forjou a sociedade.

José Guilherme Melquior, filósofo brasileiro, diz que "a arte tolerada pode gerar a crítica da sociedade que a tolera e segregar o vírus de ruptura com dita sociedade". ${ }^{7}$ Que a sociedade tolere o teatro de rua não o faz menos transgressor, porque esta tolerância está marcada por uma atitude discriminatória que permanentemente situa este teatro no seu lugar de marginalidade, que é um lugar de confronto com o padrão cultural dominante.

O simples fato de que o teatro de rua exista implica um potencial transgressor, mas, a concretização desta transgressão se manifesta em diferentes ordens. Em primeiro lugar; o teatro de rua transgride o caótico deslocamento das pessoas na ruas, pois, ainda que momentaneamente, propõe uma ruptura no uso cotidiano da rua. Recria o espaço da rua e inventa uma nova ordem, ao mesmo tempo que impõe às pessoas que caminham pela rua uma mudança: de simples pedestres a espectadores.

Em segundo lugar, ao ocupar a rua, o teatro se faz permeável à influência do que se poderia chamar "cultura da rua", que seria a mescla de todas as culturas dos usuários do espaço da rua, tudo aquilo que se manipula como modo de atuar próprio da rua; os medos, os códigos gestuais, as formas de ocupação do espaço, etc. Esta cultura da rua estaria situada fora do padrão cultural dominante, como fato paralelo e marginal.

Outro aspecto desta transgressão: o teatro de rua toma elementos das manifestações de rua, especialmente aquelas relacionadas com as lutas políticas ou sindicais. Este fenômeno responde a que, no seio destas manifestações, se desenvolveu uma maneira particular de ocupação e uso do espaço da rua que 
explicita o caráter democrático da rua. $\mathrm{O}$ teatro de rua, tão transgressor como as lutas políticas, toma emprestado a estas alguns elementos formais.

Ainda que se possam ver nas ruas manifestações artísticas que nada têm de transgressoras - especialmente naqueles casos em que as instituições da cultura levam espetáculos de âmbitos fechados aos palcos na rua, ou quando organismos oficiais de cultura realizam atividades de rua - se pode dizer que essencialmente o teatro de rua transgride o princípio hierárquico espacial dentro do qual a sociedade burguesa enquadra as manifestações artísticas, como fica explicitado no conteúdo deste capítulo.

É a partir da compreensão do teatro de rua como uma modalidade teatral transgressora que se pode começar a estudar a atitude dos regimes ditatoriais para com os grupos que realizaram este tipo de teatro e as conseqüências posteriores que sofreu o discurso teatral de rua no seio dos processos de democratização.

Este acontecimento tem uma composição híbrida. O hibridismo é uma característica fundamental da rua que é o âmbito que permite a fomenta a interferência múltipla de fatores na construção do espetáculo de rua como cerimônia pública.

A ampla diversidade de sujeitos sociais que estão aptos a interferir na construção do momento espetacular modifica o caráter do espetáculo, senão na totalidade da sua linguagem cênica, na sua relação concreta com o ambiente. Utilizando termos termos da semiótica, poderíamos dizer que até o significante do signo teatral sofre influências modificadoras na rua dado que as próprias regras que são propostas para a construção do espetáculo podem mudar (e mudam) radicalmente na relação vigorosa que se estabelece na representação na rua.

A interferência do público multifacético (multi-social) da rua tem a potencialidade de transformar o caráter do espetáculo teatral, incorporando componentes da cultura popular e construindo no evento espetacular um acontecimento da cultura popular. Um encontro entre realizadores e audiência, que também pode se dar entre campos culturais distintos, mas que se constrói como uma síntese cujo resultante é a re-apresentação da cultura popular.

Esta aparece então como fenômeno da recepção que constrói sentidos a partir do texto espetacular. Ao construir sentidos atribuindo significados ao espetáculo a cultura de rua define o teatro de rua como acontecimento que 
se incorpora a esse marco cultural. Então seria possível pensar que mesmo o espetáculo mais experimental viria a compor parte da cultura popular, ou mais especificamente da cultura híbrida das ruas.

\section{Referências Bibliográficas}

Ávila, Affonso. O lúdico e as projeções do mundo barroco. São Paulo. De. Perspectiva. 1980.

Duvignaud, Jean. El juego del juego. México. Fondo de Cultura Económica. 1982.

Jameson, Fredric. El Posmodernismo como lógica cultural del capitalismo tardio. Buenos Aires, Imago. 1996.

Melquior, José Guilherme. Formalismo e tradição moderna - O problema da arte na crise da cultura. São Paulo. Ed. Forense - EDUSP1974. 